\title{
Application of Wireless Telemeter Multiplex Transmission System to Shield Tunnelling
}

\author{
Masakazu lijima*, Shiro Shiba*, Takaichi Yamazaki*, Tuguo Iwasaki* \\ * Institute of Technology, Tekken Corporation, 9-1 Shin-izumi, Narita, Chiba, 286 JAPAN
}

\begin{abstract}
There is increasing demand for labor saving and improvement of work environment in today's construction sites, necessarily resulting in more extensive mechanization, robotization and informationintensification for different work steps. Three important technologies supporting these trends are data processing by computer, electronic communications and control techniques. Through the study by the authors focusing on the radio communications, a "Wireless Telemeter Multiplex Transmission System" has been developed. This system, based on the SS (short for Spread Spectrum) radio communication technique, is capable of multiplexing various data by relaying. The transmission system was experimentally applied to shield tunnelling to evaluate its practicability. This paper describes the summary of the system and its radio communication characteristics.
\end{abstract}

\section{INTRODUCTION}

The information necessary in tunnelling practice includes, as for data in the tunnel, work situation, information of work machines, measurement sensor data, while, as for data from the office outside the tunnel, job order, information on safety. Conventionally such data are sent through cables to the office, etc, which requires reinstallation of cables along with progress of the work. Besides, another cable line is needed when a new data channel should be provided. Since the space in the tunnel is limited, such cable installation or reinstallation needs a considerable amount of labor and time, exerting significant influence on the tunnelling work. Troubles in cable lines such as broken wire, power failure have posed problems. One of powerful solutions for the problems is radio communications technology. The author et al. have developed "Wireless Telemeter Multiplex Transmission System" which is capable of multiplexing, that is, transmitting simultaneously various types of data produced in the tunnel. Instead of conventional narrowband radio transmission technique, the system utilizes the SS (spread spectrum) radio technique characterized by long-distance transmission capability with a high resistance against noise. 
Use of this technique with several terminal stations enables data transmission over the whole area of a tunnel. This paper reports the transmission tests of the system in a shield tunnel by which some characteristics of the system were verified.

\section{WIRELESS TELEMETER MULTIPLEX TRANSMISSION SYSTEM}

\subsection{SS RADIO ${ }^{1)}$}

"SS" is short for Spread Spectrum, one of digital radio communication techniques. This technique can be summarized as follows. The modulated digital signals are modified by spreading into a $2.4 \mathrm{GHz}$ band wave. The signals treated in this way can evade adverse effects of noises and interfering wave during transmission. In the receiver, the reverse process, i.e., "unspreading" is done to restore the original signals. It can be therefore said that this communication system is excellent in resistance against noise and interference. Fig. 1 shows the schematic diagram of the principle of the SS radio transmission. Figure 1 Concept of the SS radio technique.
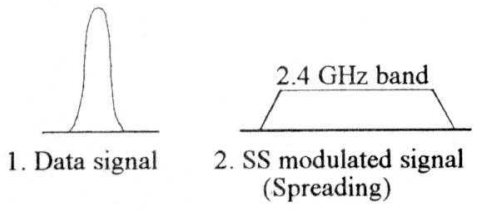
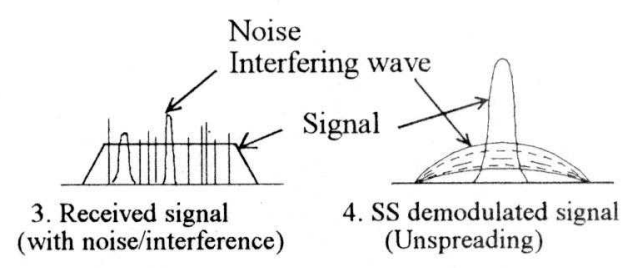

(Unspreading)

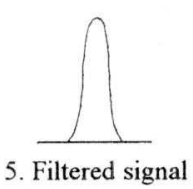

5. Filtered signal

Figure 1 Concept of The SS Radio Technique

\subsection{SYSTEM CONFIGURATION}

The system consists of multiple terminal radio station, a central radio station collecting information from the terminals and a personal computer placed in the office outside the tunnel. The personal computer manages the information. Fig. 2 shows the configuration and Table 1 the specifications of the system.

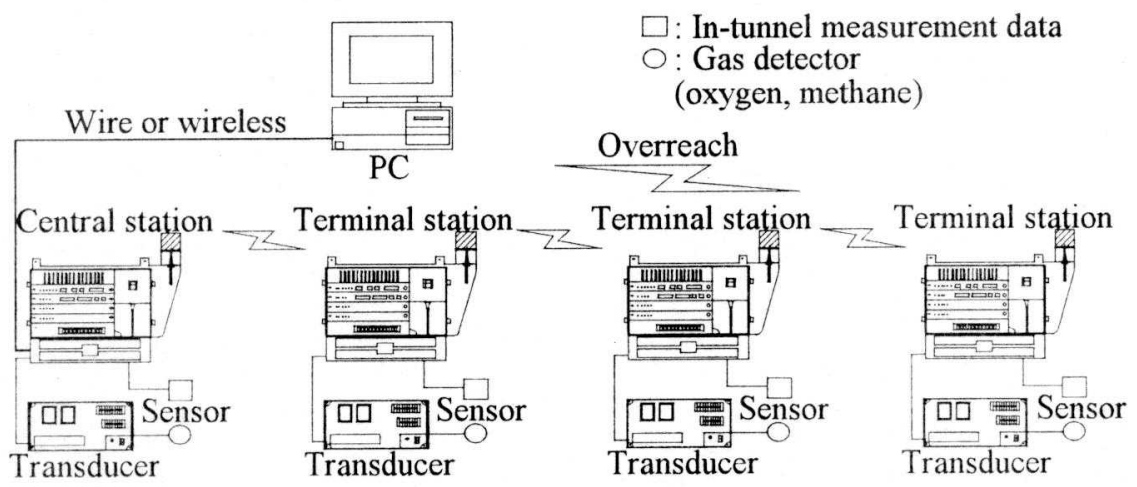

Figure 2 System Configuration 
Table 1 Specifications of The System

\begin{tabular}{|c|c|c|}
\hline \multirow{4}{*}{ 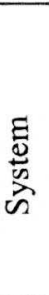 } & $\begin{array}{l}\text { No. of terminal stations } \\
\text { available in the system }\end{array}$ & Max. 254 \\
\hline & Communication system & Time-division packt transmission by relaying \\
\hline & $\begin{array}{l}\text { Backup in the event of } \\
\text { trouble }\end{array}$ & Overreach transmission/reception \\
\hline & Features & $\begin{array}{l}\text { Gathering sensor information, remote control, } \\
\text { alarm output }\end{array}$ \\
\hline \multirow{2}{*}{ 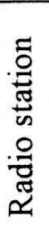 } & Sensor input & $\begin{array}{l}\text { Digital/analog input : max. } 64 \text { sensors } \\
\text { connectable }\end{array}$ \\
\hline & Radio equipment & $\begin{array}{l}\text { Modulation : spread spectrum } \\
\text { Frequency band : } 2479.0 \mathrm{MHz} \text { or } 2489.0 \mathrm{MHz} \\
\text { Transmission power : } 10 \mathrm{~mW} / \mathrm{MHz} \\
\text { Transmission rate : } 256 \mathrm{kbps}\end{array}$ \\
\hline
\end{tabular}

The central radio station gathers, by the SS radio multiplex transmission system, data from various sensors installed in different terminal radio stations in the tunnel. The gathered data are outputted to the personal computer placed in the office outside the tunnel.

\subsection{FUNCTIONS OF THE SYSTEM}

\section{(1) INFORMATION GATHERING FUNCTION}

Three methods for sensor data gathering are available at each terminal radio station: 1) regular gathering data are collected at a regular interval, 2) emergency gathering - in the event of emergency, communications are done simultaneously with the central radio station and between different terminal radio stations to transmit an alarm, and 3) transmission upon request - requested information is sent when requested. When an error occurs in gathered data, the error-check function discards the packet data concerned, to wait for new normal packet data.

\section{(2) SELF-DIAGNOSIS FUNCTION}

Terminal radio stations should be installed in such a manner that communications between them are possible. However, it is difficult to know accurately before installation the radio wave environment which can be influenced by various elements such as tunnel shape. The system presented here is provided with a self-diagnosis feature which indicates the signal transmission status, for facilitating determination of layout of stations suitable for the site conditions.

\section{(3) OVERREACHFUNCTION}

In this system terminal radio stations are arranged in series to relay sensor information. If one terminal is out of order in a conventional tandem system, the whole system cannot work. In order to avoid such inconvenience, an overreach feature (bypassing communications) is provided in this new system so that signals are transmitted skipping the terminal in trouble. This feature is a backup function. 
If radio stations are arranged in a range where radio communications are possible, the feature enables reception of information from the second nearest radio station in the event of trouble in the adjacent station.

\section{(4) TIME-DIVISION PACKET RELAY}

Downward signals to be transmitted from central station to terminals and upward signals from terminals to central station are included in a single packet of a fixed length as shown in Fig.3. Each of radio stations, both central and terminal, transmits a packet at a regular interval of 8 time spans ( $4 \mathrm{~ms}$ being a unity). Fig.4 shows the transmission timing.

Each station is designed to transmit a packet with the predetermined time delay after reception of a packet by its adjacent station. Each station, except in the transmission timing span, is set in the signal receiving status.

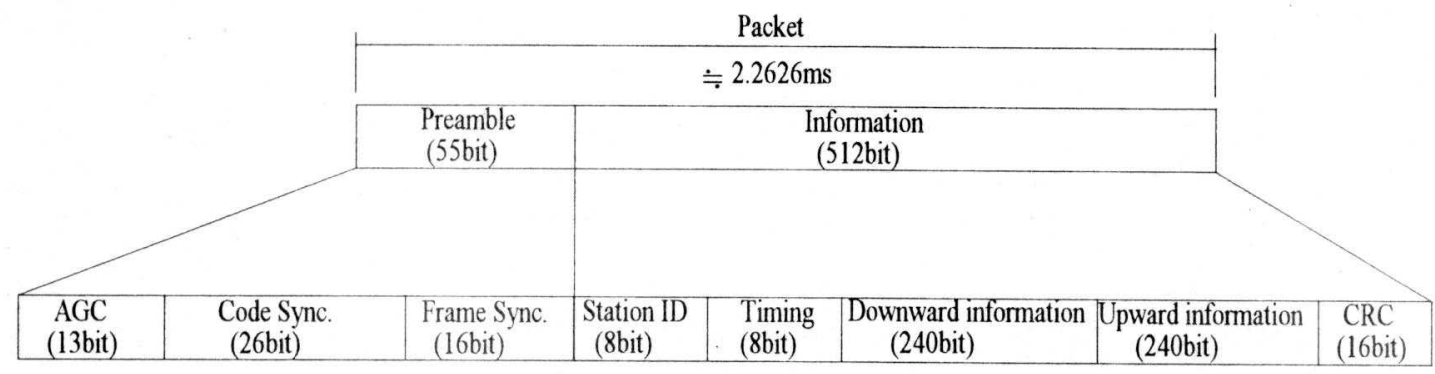

Figure 3 Configuration of Packet

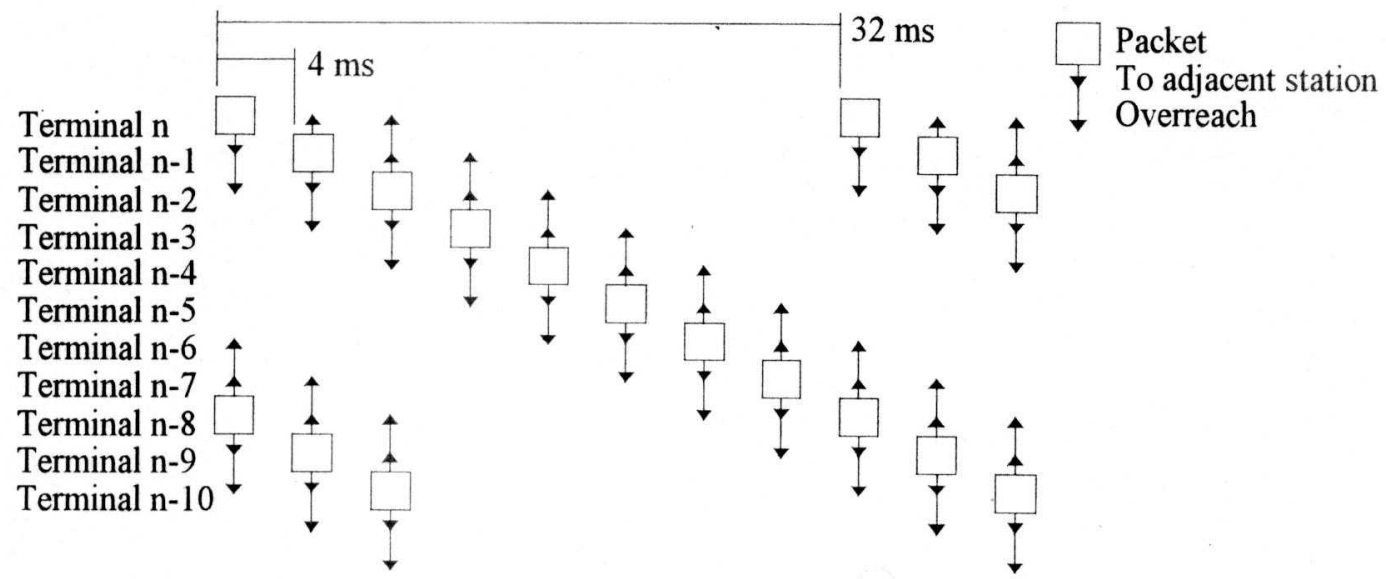

Figure 4 Transmission Timing

\subsection{MERITS OF THE SYSTEM}

The following are principal merits of the system designed with the functions discussed above.

1) Can transmit simultaneously, i.e. multiplex packets of various data by relaying.

2) Can offer reliable communications by means of the SS radio system presenting high resistance against noises and interfering waves. 
3) Enables engineers on site to grasp in real time the work status. So job orders can be given rapidly and exactly.

4) Can be extended flexibly along with the progress of work. Reinstallation of cables is not necessary.

\section{APPLICATION TO SHIELD TUNNELLING}

The field tests of radio transmission were conducted for these purposes: one is to verify that information produced in the tunnel is surely transmitted to the office by relaying via terminal radio stations, and the other is to achieve the expected reliability of data communications.

\subsection{COMMUNICATION ENVIRONMENT}

In the tunnel, mechanical equipment including shield machine, ventilators, pumps were always in operation, and segment wagons run frequently. The specifications of the tunnel to which the radio multiplex transmission system was applied are summarized in Table 2 .

Table 2 Specifications of The Tunnel

\begin{tabular}{|l|l|}
\hline Tunnelling method & Slurry shield \\
\hline Lining & Concrete segments \\
\hline Tunnel geometry & Length : $1,008.3 \mathrm{~m}$ \\
& $\begin{array}{l}\text { Inner diameter }: 5.55 \mathrm{~m} \\
\text { Curvature radii : } 400,200,150 \mathrm{~m}\end{array}$ \\
\hline
\end{tabular}

\subsection{EXPERIMENTAL RADIO TRANSMISSION}

The radio stations were installed near the high tension cable at the springline level of the tunnel. The data to be transmitted include the concentration of methane and oxygen gas, and the strain of segments. Fig. 5 illustrates the measurement locations. Fig. 6 shows the monitoring screen.

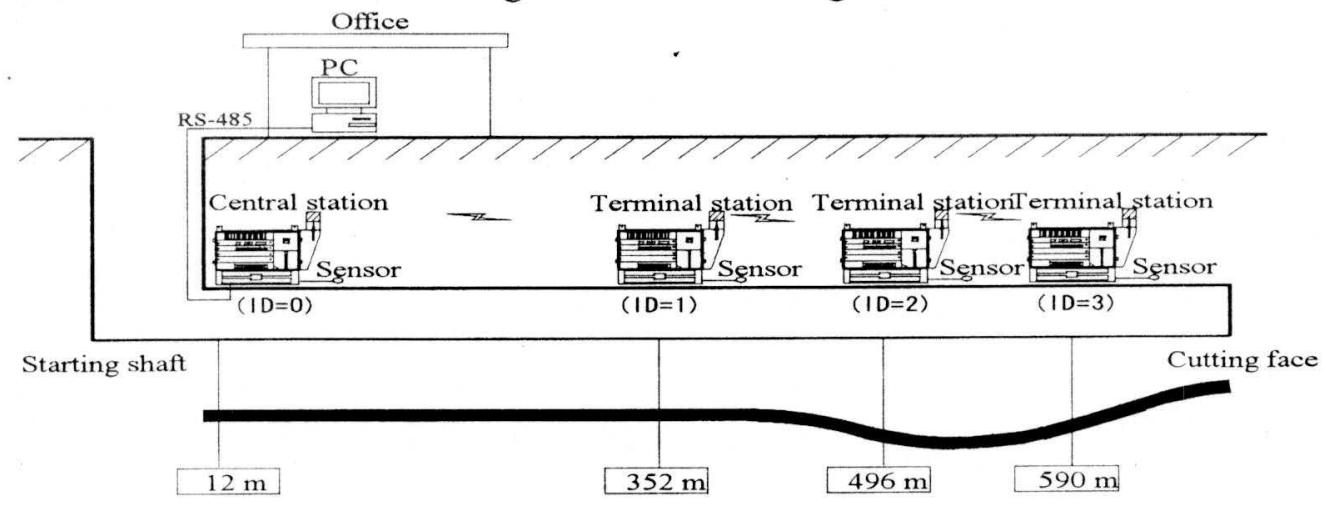

Figure 5 Measurement Positions 


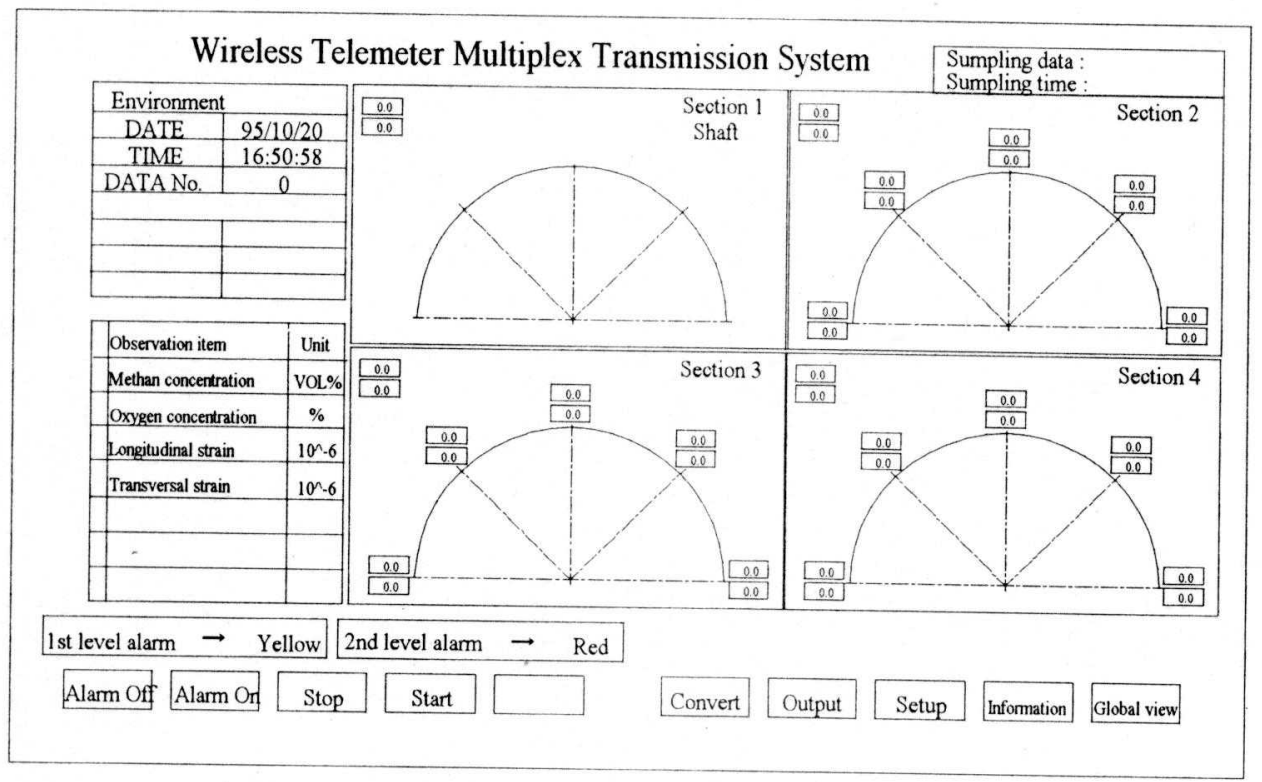

Figure 6 Monitoring Screen

\subsection{EXPERIMENTAL RESULTS}

\section{(1) RELAYING TYPE DATA MULTIPLEX TRANSMISSION}

The data coming from the sensors connected to each terminal radio station were sampled at an interval of 10 seconds, which could be displayed in real time on the personal computer screen (Fig. 6).

\section{(2) MEASUREMENT OF ERROR RATE AT EACH TERMINAL RADIO STATION}

Four radio stations installed in the tunnel were operated simultaneously for about one hour, to obtain the number of packets transmitted and received, and the number of receiving errors. Table 3 shows the error rates (rate of receiving errors to the total transmissions) of the system during continuous operation. Though the error rates for receiving between adjacent stations were several percent, satisfactory function of the system is ensured by the features of error-data discarding and retransmission of correct data.

Table 3 Error rates

\begin{tabular}{|l|r|r|r|r|}
\hline \multirow{2}{*}{$\begin{array}{l}\text { Transmitting } \\
\text { station }\end{array}$} & \multicolumn{4}{|c|}{ Receiving station } \\
\cline { 2 - 5 } & $\mathrm{ID}=0$ & $\mathrm{ID}=1$ & $\mathrm{ID}=2$ & $\mathrm{ID}=3$ \\
\hline $\begin{array}{l}\text { Central station } \\
(\mathrm{ID}=0) \text { error rate }\end{array}$ & & 4.1 & 12.3 & 99.9 \\
\hline $\begin{array}{l}\text { Terminal station } \\
(\mathrm{ID}=1) \text { erroe rate }\end{array}$ & 0.0 & & 7.9 & 16.3 \\
\hline $\begin{array}{l}\text { Terminal station } \\
(\mathrm{ID}=2) \text { error rate }\end{array}$ & 12.4 & 0.0 & & 4.2 \\
\hline $\begin{array}{l}\text { Terminal station } \\
(\mathrm{ID}=3) \text { error rate }\end{array}$ & 99.9 & 100.0 & 0.0 & \\
\hline
\end{tabular}




\section{(3) ALARMING BY GAS DETECTION}

For the methane sensors and oxygen sensors, reference values were set up for the 1st level alarm and 2nd level alarm

The alarming function was verified using test gas, both in the tunnel and on the personal computer screen

\section{(4) TRANSMITTABLE DISTANCE}

With the central radio station fixed, displacing one of the terminal radio stations, the transmittable distance was measured.

The result shows transmission over a distance of about $550 \mathrm{~m}$ is available, which is about 100 times as large as the tunnel diameter of $5.55 \mathrm{~m}^{2)} \mathrm{Fig} .7$ shows the error rate vs transmission distance.

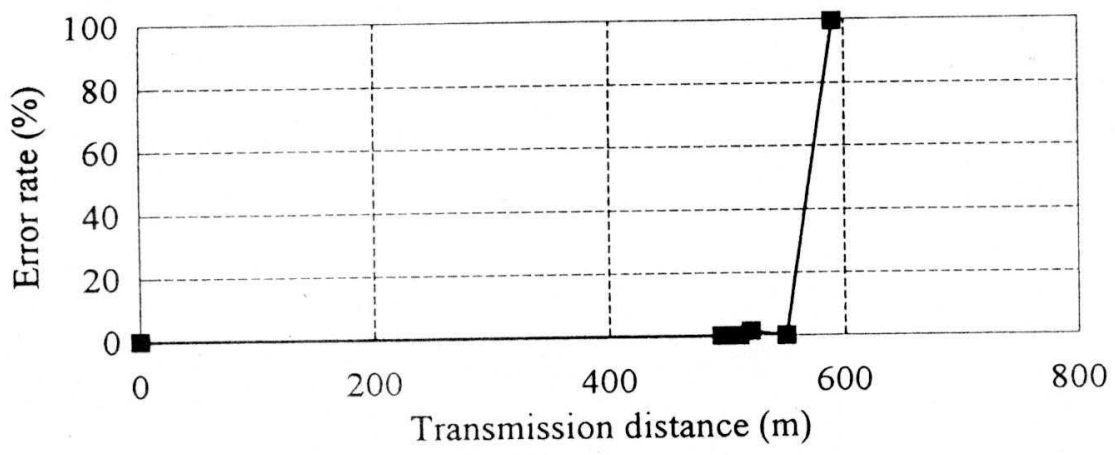

Figure 7 Error Rate vs Transmission Distance

\section{(5) INFLUENCE EXERTED BY THE EQUIPMENT IN THE TUNNEL}

No significant influence was exerted by the equipment in the tunnel such as high tension cables, pumps, or noises from segment wagons, interfering waves.

The experiments discussed above verified the excellent features of the relaying radio multiplex transmission system and reliability of the transmitted data, enabling establishment of a radio communication technique for tunnelling work.

\section{TARGETS FOR FURTHER DEVELOPMENT}

The following are the targets for application of the radio communication system to fields other than tunnelling, and for unmanned operation of construction machines, or robotization.

1) More compact and lightweight radio stations

2) Integration of the developed system with image transmission

3) Development of multimedia transmission system including voice-transmission capability

4) Enlargement of the system for management of mobile equipment 


\section{CONCLUSIONS}

Use of radio system in tunnelling sites has been deemed difficult.

The research and experiments however have verified the sufficient applicability of the wireless telemeter multiplex transmission system based on the spread spectrum technique to tunnelling work, which presents high resistance against noise and interference. Each of the radio stations arranged at a regular interval can transmit simultaneously various measurement data at a time. This function enables engineers at the office to grasp in real time the situation inside the tunnel.

The communication system presented in this paper will contribute to information-intensification, labor saving and rationalization of work steps. It is also applicable to data transmission in fields other than tunnelling such as work near railway, bridge, dam construction sites. Besides, by integrating the radio communication system with the control technology for construction machines and robots, unmanned or robotized operation of construction machine will be available.

\section{REFERENCES}

1) Y. Yamanouchi; Spread spectrum communication : toward the functional communication of the next generation, Publishing Bureau of Tokyo Denki University

2) Iijima, Shiba, Yamazaki, Tanabe; On the system for image and data transmission by the SS radio technique in tunnelling : Proceedings of the 50 th Seminar of Japan Society of Civil Engineers VI-145 pp 290 to 291, September 1995 